\title{
The uptake and metabolism of retinol, retinoic acid and methyl retinoate by the early chick embryo
}

\author{
By B. MORGAN,* J. N. THOMPSON† and G. A. J. PITT \\ Department of Biochemistry, University of Liverpool
}

(Received 9 April I969-Accepted 25 April 1969)

\begin{abstract}
1. Fertile eggs deficient in vitamin A were obtained by feeding hens a diet deficient in retinol (vitamin $\mathrm{A}$ alcohol) but containing methyl retinoate.

2. Radioactive retinol was injected into the albumen of three of these eggs at a level of $2 \mu \mathrm{g}$ $\left[6,7-{ }^{14} \mathrm{C}\right] \mathrm{retinol} / \mathrm{egg}$. After 5 days' incubation, $4 \cdot 6-8 \cdot 3 \%$ of the injected material was recovered in the lipid of the embryo, representing a four- to nine-fold concentration into the embryo from the albumen. Approximately $40-50 \%$ of this was unchanged retinol, $15-20 \%$ retinaldehyde and $20-30 \%$ probably a long-chain fatty acid retinyl ester. The early embryo can, therefore, metabolize vitamin A very effectively.

3. $\left[6,7^{-14} \mathrm{C}\right]$ Retinoic acid $(2 \mu \mathrm{g})$ was injected into normal fertile eggs, killing most of the embryos. The eggs with dead embryos were analysed; $0.24 \%$ and $0.33 \%$ of the injected material was recovered from the embryos. Two embryos which developed contained $0.51 \%$ and $0.53 \%$ of the injected dose. In no instance was any material identified other than retinoic acid. The extremely low amounts of retinoic acid absorbed by the embryos emphasize the very high toxicity of retinoic acid to the early chick embryo.

4. $\left[6,7^{14} \mathrm{C}\right]$ Methyl retinoate $(0.5 \mu \mathrm{g})$ was injected into each of four normal eggs; $8 \cdot 5-1 \mathrm{I} \cdot 6 \%$ was isolated as unchanged methyl retinoate after 5 days; no other radioactive substance was detected.
\end{abstract}

The normal hen's egg contains enough vitamin A in the yolk to meet the needs of the developing chick for $2-3$ weeks after hatching. The vitamin A in unincubated eggs is mainly in the form of retinol. Carotenoids and retinyl esters are also present in much smaller amounts (Neff, Parrish, Hughes \& Payne, 1949), as is retinaldehyde (Plack, I $963 a, b$ ). Plack, Miller \& Ward (1964) suggested that the quantities of retinol, retinyl esters and retinaldehyde present in the egg reflect their concentration in the blood of the hen at the time of yolk deposition.

Parrish, Williams \& Sanford (I95I) found that, from the 2nd week of incubation onwards, the developing embryo changes the proportion of retinyl ester to retinol, so that at the time of hatching, retinyl esters constitute the major part of the vitamin $A$. Plack $\left(\mathrm{I} 6_{3} b\right)$ observed that only $16 \%$ of the retinaldehyde originally in the egg was present in the chick.

These findings indicate that, as the chick embryo grows, it metabolizes the yolk stores of retinol and retinaldehyde to form retinyl esters. None of these effects has been detected before the Ioth day of incubation.

Thompson, Howell, Pitt \& Houghton (1965) demonstrated that the chick embryo needs vitamin A as early as the 2nd day of incubation and, at this state, the embryo was able to utilize all forms of the vitamin.

* Present address: Beecham Research Laboratories, Vitamins Research Station, Walton Oaks, Tadworth, Surrey.

$\uparrow$ Present address: Department of Poultry Science, Cornell University, Ithaca, N.Y. I4580, USA. 
The significance of the metabolic interconversions to the embryo's need for vitamin $A$ is not at present understood. Fertilized eggs free from vitamin A can now be obtained by the procedure of Thompson, Howell, Pitt \& McLaughlin (1969). Hens are fed a diet deficient in retinol but containing methyl retinoate (the methyl ester of retinoic acid). It is possible to study the metabolism of vitamin A during the time that it stimulates embryonic development by injecting radioactive retinol into such eggs. Thompson et al. (1965, 1969) also found that retinoic acid (vitamin A acid) was very toxic to the early chick embryo, but that its methyl ester would stimulate development of the vitamin A-deficient embryo. Therefore, the uptake of radioactive retinoic acid and methyl retinoate has also been investigated in the early chick embryo.

\section{EXPERIMENTAL}

Eggs. Normal fertile eggs were purchased from a local farmer. Vitamin A-deficient eggs were obtained as described by Thompson $e$ t al. (1965, 1969). Before setting the eggs, substances were injected by the procedure of Thompson et al. (1969) in $0.2 \mathrm{ml}$ $0.9 \% \mathrm{NaCl}$ solution containing $0.1 \%$ Tween 40 . The eggs were incubated for 5 days and the embryos plus yolk sac membrances were then removed for analysis.

Vitamin $A$ derivatives. $\left[6,7^{-14} \mathrm{C}\right]$ Retinoic acid $\left(\mathrm{r} 9^{\cdot} 9 \mu \mathrm{c} / \mathrm{mg}\right)$ was a gift from $\mathrm{Dr} O$. Isler, Hoffman-La Roche and Co. (Basle). $\left[6,7-{ }^{14} \mathrm{C}\right]$ Retinol was prepared by reduction of $\left[6,7^{-14} \mathrm{C}\right] \mathrm{retinoic}$ acid with lithium aluminium hydride in dry diethyl ether. The product was purified by chromatography on columns of alumina. $\left[6,7^{-14} \mathrm{C}\right]$ Methyl retinoate was prepared from $\left[6,7^{14} \mathrm{C}\right]$ retinoic acid by the method of Robeson (1952). All radioactive substances used were chromatographically pure on thin-layer chromatograms.

Radioactivity measurements. Radioactivity was assayed in a Tri-carb scintillation counter (Model 3 I 4 Ex.; Packard Instrument Co., USA). The scintillation fluid contained $5 \mathrm{~g} \mathrm{2,5-diphenyloxazole} \mathrm{and} 0.3 \mathrm{~g}$ I,4-bis-2-(4-methyl-5-phenyloxazolyl)benzene per l. toluene. Activity was corrected for quenching using internal standards of $\left[{ }^{14} \mathrm{C}\right]$ toluene. Radioactivity on thin-layer chromatograms was measured on an Actigraph III scanner model 1002.

Chromatography. Thin-layer chromatography was performed on $250 \mu \mathrm{m}$ layers of Kieselgel $\mathrm{G}$ unless otherwise stated. Spots were detected either under ultraviolet light or after staining with iodine vapour.

Column chromatography was performed on either Woelm grade III acid-washed alumina or silicic acid-celite $2: \mathrm{I}(\mathrm{w} / \mathrm{w})$.

Analysis of embryos. Lipids were extracted from embryos by grinding with silver sand and chloroform-methanol $2: \mathrm{I}(\mathrm{v} / \mathrm{v})$. An equal volume of water was added, and the chloroform layer separated by centrifugation for $5 \mathrm{~min}$ at $500 \mathrm{~g}$. The aqueous phase was removed, and the chloroform layer evaporated to dryness under reduced pressure. The residue was dissolved in light petroleum (boiling range $40-60^{\circ}$ ).

In experiments with retinol, the lipid extracts were chromatographed on columns of alumina using the solvent system of Huang \& Goodman (1965) modified by the omission of their first fraction, eluted with hexane. The fractions obtained were eluted 
as follows: fraction I was eluted with benzene-hexane $(3: 17, v / v)$, fraction 2 with benzene-hexane $(\mathrm{I}: \mathrm{I}, \mathrm{v} / \mathrm{v})$, fraction 3 with benzene, fraction 4 with methanol and fraction 5 with methanol- $25 \%$ acetic acid $(3: \mathrm{I}, \mathrm{v} / \mathrm{v})$. The following were added as carriers to the extracts before chromatography: retinyl acetate $(200 \mu \mathrm{g})$, retinaldehyde $(100 \mu \mathrm{g})$, retinol $(100 \mu \mathrm{g})$ and retinoic acid $(200 \mu \mathrm{g})$. After elution from the column, each fraction was chromatographed on thin-layer plates in a solvent system designed so that the carrier vitamin $A$ derivative present in that particular fraction would have an $R_{F}$ value of approximately 0.5 ('Table 1 ).

\section{Table I. Solvent systems used for thin-layer chromatography of fractions obtained after alumina column chromatography of chick embryo lipid}

$\begin{array}{cl}\begin{array}{c}\text { Fraction } \\ \text { no. }\end{array} & \begin{array}{c}\text { Carrier compound } \\ \text { present }\end{array} \\ \mathbf{x} & \text { Retinyl acetate } \\ 2 & \text { Retinaldehyde } \\ 3 & \text { Retinol } \\ 4 & - \\ 5 & \text { Retinoic acid }\end{array}$

Adsorbent
on plate

Alumina

Silica gel G

Silica gel G

Silica gel G

Silica gel $\mathrm{G}$

\section{Solvent system}

$25 \%(\mathrm{v} / \mathrm{v})$ benzene in hexane $15 \%(v / v)$ ethyl acetate in petrol $20 \%(\mathrm{v} / \mathrm{v})$ ethyl acetate in petrol $33 \%(\mathrm{v} / \mathrm{v}$ methanol in benzene Methylal

\section{RESULTS}

\section{Retinol}

Three vitamin A-deficient eggs were each injected with $2 \mu \mathrm{g}\left[6,7^{14} \mathrm{C}\right]$ retinol. After 5 days' incubation, the embryos plus associated membranes, which appeared normal and had thus been stimulated by the labelled vitamin, were removed and analysed.

The proportions of the injected dose recovered in the total lipid of each embryo were $8.3 \%, 4.6 \%$ and $7.4 \%$. The distribution of radioactivity among the column fractions is shown in Table 2. After thin-layer chromatography, results were obtained as follows:

Table 2. Radioactivity recovered after alumina column chromatography of embryo lipid 5 days after injection of $2 \mu g\left[6,7^{-14} C\right]$ retinol into vitamin $A$-deficient hens' eggs

\begin{tabular}{|c|c|c|c|c|}
\hline \multirow[b]{2}{*}{$\begin{array}{c}\text { Fraction } \\
\text { no. }\end{array}$} & \multirow[b]{2}{*}{$\begin{array}{l}\text { Detectable radioactive } \\
\text { constituent }\end{array}$} & \multicolumn{3}{|c|}{$\begin{array}{l}\text { Percentage of total radioactivity } \\
\text { recovered from column }\end{array}$} \\
\hline & & $\begin{array}{l}\text { Egg } \\
\text { no. } \mathrm{r}\end{array}$ & $\begin{array}{l}\text { Egg } \\
\text { no. } 2\end{array}$ & $\begin{array}{l}\text { Egg } \\
\text { no. } 3\end{array}$ \\
\hline I & Retinyl ester & $32 \cdot 2$ & $21 \cdot 2$ & $22 \cdot 8$ \\
\hline 2 & Retinaldehyde & 15.7 & 15.0 & $20 \cdot I$ \\
\hline 3 & Retinol & $\mathrm{r} 9.0\}_{38.6}$ & $29 \cdot 2\}_{52 \cdot 7}$ & $25^{\circ}$ ) \\
\hline 4 & Retinol & $19.6\}^{38.6}$ & $23.5\}^{52 \cdot 7}$ & $23.9\}$ \\
\hline 5 & - & 13.5 & II.T & $8 \cdot 2$ \\
\hline
\end{tabular}

Fraction I. The radioactivity herein was confined to one peak which had an $R_{F}$ higher than that of retinyl acetate but similar to that of retinyl palmitate. This indicates that the radioactive metabolite present is probably a long-chain ester of retinol.

Fraction 2. The activity was confined to one peak, the position of which coincided with the position of retinaldehyde on the chromatogram. 
Fraction 3. The single peak of radioactivity observed on the chromatogram of this fraction migrated to the same position as carrier retinol.

Fraction 4. Some of the carrier retinol added to the lipid extract was detected spectrophotometrically in this fraction as well as in fraction 3. On thin-layer chromatography, a single radioactive peak was obtained, in the position of retinol.

Fraction 5 . The radioactivity in fraction 5 was distributed evenly over the chromatogram, and no distinct peak was observed. The radioactivity in this fraction probably represents breakdown products of retinol, formed either in vivo or, more likely, as artifacts.

Summary. Of an injected dose of $2 \mu \mathrm{g}$ retinol, $4-9 \%$ was taken up by the vitamin A-deficient chick embryo and its membranes from the egg albumen during the first 5 days of development. Approximately $40-50 \%$ of this could be detected as unchanged retinol, while a further $20-30 \%$ was probably esterified with a long-chain fatty acid. In addition, a significant proportion of radioactivity taken up by the embryo ( $15-20 \%)$ was present as retinaldehyde.

A sample of albumen was taken from egg no. 2, carrier retinol (100 $\mu \mathrm{g}$ ) was added, and the lipid was extracted. The extract was chromatographed on thin layers in $2: \mathrm{I}$ $(\mathrm{v} / \mathrm{v})$ benzene-methanol. A single radioactive peak was observed, chromatographically identical with retinol.

\section{Retinoic acid}

Normal fertile eggs were injected with $2 \mu \mathrm{g}\left[6,7^{-14} \mathrm{C}\right]$ retinoic acid. Of twenty eggs treated in this way, only two showed normal embryonic development. In the remaining eighteen eggs, development had been arrested at an early stage. The two normal embryos and two dead embryos were removed for analysis. Carrier retinoic acid (100 $\mu \mathrm{g}$ ) was added to each embryo and the lipid was extracted. The lipid extracts were subjected to thin-layer chromatography in $2: \mathrm{I}(\mathrm{v} / \mathrm{v})$ benzene-methanol.

The total contents (yolk + dead embryo + albumen) of another egg were also extracted with chloroform-methanol (2:I) (v/v). After addition of carrier retinoic acid $(200 \mu \mathrm{g})$, the extract was chromatographed on a column of silicic acid, using increasing concentrations of diethyl ether in light petroleum as eluents.

In the two normal embryos, $0.5 \mathrm{I} \%$ and $0.53 \%$ of the injected dose of radioactivity were recovered. A lower yield $(0.24 \%$ and $0.33 \%)$ of radioactivity was obtained with the dead embryos. On thin-layer chromatography, a single radioactive peak was obtained, chromatographically identical with retinoic acid.

On extraction of the total contents of an egg, $89 \%$ of the injected dose was recovered in the lipid extract. Most of the radioactivity $(80 \%)$ was eluted from a silicic acid column with carrier retinoic acid, using $12-20 \%(\mathrm{v} / \mathrm{v})$ ether in petrol. The remaining radioactivity was distributed evenly over the other fractions from the column.

\section{Methyl retinoate}

$\left[6,7^{-14} \mathrm{C}\right]$ Methyl retinoate $(0.5 \mu \mathrm{g})$ was injected into each of four normal eggs. The embryos were removed after 5 days' incubation and the total lipid was analysed.

The recoveries of radioactivity obtained in the four embryos were $10 \cdot 9,8 \cdot 7, \mathrm{II} \cdot 6$ and $9.5 \%$ of the dose. The extracts were co-chromatographed with methyl retinoate 
on thin layers in benzene, and each chromatogram showed a single radioactive peak chromatographically identical with methyl retinoate. Carrier methyl retinoate ( $\mathrm{mg}$ ) was added to one of the extracts, which was then saponified by the method of Idler $\&$ Baumann (1952). The saponified extract was chromatographed on a thin layer in $2: 1$ $(\mathrm{v} / \mathrm{v})$ benzene-methanol. The chromatogram had a single radioactive peak running with retinoic acid. This confirms that the radioactivity detected in the embryo was attributable to unchanged methyl retinoate.

The yolk from one of the eggs was also analysed. The radioactivity detected in the yolk accounted for $86 \%$ of the injected dose of activity. Of the radioactivity detected in the yolk, $87 \%$ was eluted with petrol from a column of silicic acid. After thin-layer chromatography in benzene, the radioactivity in the petrol fraction was concentrated in a single peak which ran with methyl retinoate.

\section{DISCUSSION}

The growth of vitamin A-deficient chick embryos was stimulated by injecting as little as $2 \mu \mathrm{g}$ retinol into the egg before incubation. After 5 days, $4 \cdot 6-8 \cdot 3 \%$ of this injected dose was detected in the embryos and its membranes. The major radioactive compound present in the embryo was unchanged retinol. However, retinyl ester (probably a long-chain ester such as retinyl palmitate) and retinaldehyde were also found in appreciable quantities. No unidentified peaks of radioactivity were detected on the thin-layer chromatograms. There was, therefore, no evidence of any metabolite which could be implicated as an active form of vitamin $A$, as has at times been suggested (see, for example, Perumal \& Cama, I967).

Table 3. Proportions of vitamin A derivatives found in normal eggs by Plack (1960, 1963a) compared with those in 5-day chick embryos (present work)

(Values are expressed as percentages of total identified derivatives: means, with range of values)

$\begin{array}{lcc} & \begin{array}{c}\text { Eggs } \\ \text { (Plack, I960, I963a) }\end{array} & \begin{array}{c}\text { 5-day embryos } \\ \text { (present work) }\end{array} \\ \text { Retinol } & 7 \mathrm{I} \cdot 9(68 \cdot 2-76 \cdot 6) & 52 \cdot 4(44 \cdot 6-59 \cdot 3) \\ \text { Retinyl esters } & 14 \cdot 8(\mathrm{I} \cdot 8-\mathrm{I} 6 \cdot 8) & 28 \cdot 6(23 \cdot 8-37 \cdot 2) \\ \text { Retinaldehyde } & 13 \cdot 3(10 \cdot 5-16 \cdot 8) & \text { I9.0 }(6 \cdot 9-2 \mathrm{I} \cdot 9)\end{array}$

Plack (1960, I963a) analysed the vitamin A contents of fresh eggs from hens fed a normal breeder's mash. Table 3 compares the values calculated from the results with those presented in this paper. (The figures differ slightly from those given in Table 2, as the radioactive breakdown products have been omitted, to make our figures comparable with those of Plack.)

Parrish et al. (I95I) analysed developing eggs and found esterification of retinol taking place from the roth day of incubation; their techniques were not sensitive enough to detect earlier changes. Our results show that the embryo is capable of esterifying retinol during the first 5 days of development. The percentage of vitamin A detected as retinyl ester in 5 -day embryos is significantly higher than that normally present in unincubated eggs, while the opposite applies to retinol (Table 3). This 
process presumably continues throughout development until hatching, when most of the vitamin $A$ in the chick is present as retinyl ester (Parrish et al. I95 I Plack, $1963 b$ ). Furthermore, the early embryo is able to convert retinol into retinaldehyde. It is clear that the embryo itself, plus extra-embryonic membranes, is responsible for the conversion of retinol to retinyl esters and retinaldehyde, as the only form of vitamin A found in the rest of the egg was retinol itself.

Five days after injecting $0.5 \mu \mathrm{g}$ methyl retinoate into the egg, approximately $10 \%$ of the dose was detected in the embryo. Virtually all of this was unchanged methyl retinoate. A further $86 \%$ of the injected dose was found unchanged in the yolk. No free retinoic acid or any metabolite was identified. It seems reasonable to assume that when it promotes growth in a vitamin A-deficient embryo (Thompson et al. 1965, 1969), methyl retinoate works as such.

Several 5-day embryos were weighed and were found to constitute approximately I $\%$ of the wet weight of the egg contents. The fact that the embryo can contain up to $10 \%$ of an injected dose of retinol or methyl retinoate after 5 days of incubation demonstrates the efficiency of absorption and concentration of these substances from the albumen into embryonic tissue.

The two embryos killed by retinoic acid were found to contain only $0.24 \%$ and $0.33 \%$ of a dose of $2 \mu \mathrm{g}$ retinoic acid and nearly all the injected material was recovered elsewhere in the egg. The amount effective in the embryo itself is, therefore, minute. The mechanism of this remarkably high toxicity deserves further study.

This work was supported in part by US Public Health Service Grant AM-05282-021. B. Morgan was in receipt of a Medical Research Council Research Studentship and J. N. Thompson was a British Egg Marketing Board Fellow.

\section{REFERENCES}

Huang, H. S. \& Goodman, D. S. (1965). F. biol. Chem. 240, 2839.

Idler, D. R. \& Baumann, C. A. (1952). F. biol. Chem. 195, 623.

Neff, A. W., Parrish, D. B., Hughes, J. S. \& Payne, L. F. (1949). Archs Biochem. 21, 315.

Parrish, D. B., Williams, R. N. \& Sanford, P. E. (I95I). Archs Biochem. 34, 64.

Perumal, A. S. \& Cama, H. R. (1967). Indian f. Biochem. 4, I52.

Plack, P. A. (1960). Nature, Lond. 186, 234.

Plack, P. A. (1963a), Br. $\mathscr{~}$. Nutr. 17, 235.

Plack, P. A. (1963b). Br. F. Nutr. 17, 243.

Plack, P. A., Miller, W. S. \& Ward, C. M. (1964). Br. F. Nutr. 18, 275.

Robeson, C. D. (1952). U.S. Patent no. 2583594 .

Thompson, J. N., Howell, J. McC., Pitt, G. A. J. \& Houghton, C. I. (1965). Nature, Lond. $205,1006$. Thompson, J. N., Howell, J. McC., Pitt, G. A. J. \& McLaughlin, C. I. (1969). Br. F. Nutr. 23, 47 I. 